\title{
PENINGKATAN PEMAHAMAN KONSEP FISIKA MAHASISWA MELALUI PENDEKATAN PEMBELAJARAN PEMECAHAN MASALAH BERBASIS VIDEO
}

\author{
Mariati Purnama Simanjuntak \\ Prodi Pascasarjana Universitas Negeri Medan \\ Mariatips@yahoo.co.id
}

\begin{abstract}
Abstrak. Penelitian ini bertujuan untuk meningkatkan pemahaman konsep mahasiswa pada matakuliah Fisika Umum melalui pendekatan pembelajaran pemecahan masalah berbasis video. Metode penelitian yang digunakan adalah pra-eksperimental dengan desain One Group Pretest-Posttest Design. Data pemahaman konsep Fisika dikumpulkan dengan tes berbentuk pilihan berganda. Peningkatan pemahaman konsep Fisika mahasiswa dinilai berdasarkan perbandingan rerata nilai gain yang dinormalisasi, $N$-gain . Hasil penelitian menunjukkan bahwa melalui penggunaan pendekatan pembelajaran pemecahan masalah berbasis video pada topik Kinematika dan Dinamika Partikel dapat meningkatkan pemahaman konsep fisika mahasiswa, termasuk kategori sedang.
\end{abstract}

Kata kunci: pendekatan pembelajaran pemecahan masalah, pemahaman konsep, berbasis video, kinematika dan dinamika partikel.

\section{Pendahuluan}

Salah satu tujuan mahasiswa mempelajari Fisika Umum adalah untuk mengembangkan pemahaman konsep Fisika sehingga dapat diterapkan dalam kehidupan sehari-hari dan sebagai bekal untuk melanjutkan pada jenjang selanjutnya. Pernyataan ini mengandung makna bahwa selain untuk kepentingan pengembangan dan penerapan dalam kehidupan sehari-hari dan teknologi, pemahaman konsep-konsep dan prinsip-prinsip Fisika merupakan persyaratan keberhasilan belajar Fisika dan meningkatnya minat mahasiswa terhadap Fisika Umum dan Fisika lanjut nantinya. Oleh karena itu diperlukan pendekatan pembelajaran yang dapat mengembangkan pemahaman konsep mahasiswa.

Gagasan pengembangan pemahaman konsep Fisika bagi mahasiswa dilandasi oleh beberapa konsepsi teoretis: (1) Konsepsi Fisika merupakan subyek yang senantiasa mengalami perubahan (Wenning, 2006). (2) Learning physics is not about memorizing facts, it is about comprehension and mathematics (Zhaoyao, 2002). Berdasarkan penjelasan teoritis tersebut, pemahaman merupakan kata kunci dalam pembelajaran. Beberapa konsepsi teoretis yang melandasi kesimpulan tersebut adalah sebagai berikut: (1) Jika tujuan pembelajaran menumbuhkan kemampuan transfer, dari lima ranah kognitif (memahami, mengaplikasikan, menganalisis, mengevaluasi, dan mencipta), maka proses kognitif yang berpijak pada kemampuan transfer dan ditekankan di sekolah-sekolah dan perguruan tinggi ialah memahami (Anderson, et al., 2002). (2) Salah satu tujuan pendidikan adalah memfasilitasi peserta didik mencapai pemahaman yang dapat diungkapkan secara verbal, numerikal, kerangka pikir positivistik dan kerangka pikir kehidupan berkelompok (Gardner, 1999). (3) Pemahaman adalah suatu proses mental terjadinya adaptasi dan transformasi ilmu pengetahuan (Gardner, 1999). (4) Pemahaman merupakan landasan bagi peserta didik untuk membangun wawasan. (5) 
Pemahaman merupakan indikator unjuk kerja yang siap direnungkan, dikritik, dan digunakan oleh orang lain. (6) Pemahaman merupakan perangkat baku program pendidikan yang merefleksikan kompetensi (Yulaelawaty, 2002).

Salah satu pendekatan pembelajaran yang ditenggarai efektif meningkatkan pemahaman konsep mahasiswa adalah melalui pembelajaran pemecahan masalah. Pendekatan pembelajaran ini merupakan pembelajaran dengan serangkaian strategi pengajaran yang dipilih dan ditetapkan dalam pembelajaran untuk menciptakan proses belajar mengajar agar mahasiswa dengan mudah memperoleh konsep dan hubungan antar konsep dalam Fisika melalui proses pemecahan masalah (Kuo, 2004).

Pembelajaran Fisika melalui pendekatan pemecahan masalah didesain dengan menyajikan masalah-masalah kepada mahasiswa. Masalah yang dimaksud bukan soal-soal Fisika yang lebih menekankan pada manipulasi matematis yang biasanya mereka dapat selama ini, melainkan masalah-masalah konstekstual yang ada dalam kehidupan sehari-hari. Mahasiswa memecahkan masalah dengan melakukan penyelidikan melalui eksperimen yang direkam dengan menggunakan video dan hasil rekaman dianalisis dengan bantuan software tracker. Tahap-tahap pemecahan masalah yang digunakan adalah: memilih dan mendesain peralatan; membuat prediksi; menjawab pertanyaan metode; melakukan eksplorasi; melakukan pengukuran; melakukan analisis; dan membuat kesimpulan (Heller and Heller, 1999).

Pendekatan pembelajaran pemecahan masalah ini mencirikan student centered, mahasiswa mengkonstruksi pengetahuan sendiri, dan mengembangkan pemahaman konsep secara aktual. Dengan demikian, diharapkan kompetensikompetensi yang dituntut dalam kurikulum dapat dikembangkan dengan baik.

\section{METODE PENELITIAN}

Penelitian ini menggunakan metode praeksperimental dengan desain One Group Pretest-
Posttest Design. Subjek penelitian ini adalah mahasiswa calon guru Fisika yang telah mengontrak mata kuliah Fisika Umum, sebanyak 47 orang pada salah satu pergurun tinggi negeri di Sumatera Utara Tahun Akademik 2010/ 2011. Tes pemahaman konsep berbentuk pilihan ganda dikumpulkan dengan 40 butir pada topik Kinematika Partikel dan 45 butir pada topik Dinamika Partikel.

Peningkatan pemahaman konsep fisika mahasiswa dinyatakan dalam persentase rerata skor gain yang dinormalisasi (N-gain). N-gain dihitung dengan persamaan yang dikembangkan oleh Hake dan Richard (2002), dimana:

$$
\% g=\frac{S_{\text {post }}-S_{\text {pre }}}{S_{\text {maks }}-S_{\text {pre }}} \times 100 \%
$$

dengan $g$ adalah gain yang dinormalisasi, Smaks adalah skor maksimum (ideal) dari tes awal dan tes akhir, Spost adalah skor tes akhir, sedangkan Spre adalah skor tes awal. Tinggi rendahnya Ngain dapat diklasifikasikan sebagai berikut: (1) jika $g>70 \%$, maka N-gain yang dihasilkan dalam kategori tinggi, (2) jika 30\% $\leq g \leq 70 \%$, maka N-gain yang dihasilkan dalam kategori sedang, dan (3) jika $g<30 \%$, maka $\mathrm{N}$-gain yang dihasilkan dalam kategori rendah.

\section{HASIL DAN PEMBAHASAN}

Rerata skor tes awal, tes akhir, dan \% Ngain pemahaman konsep pada topik Kinematika dan Dinamika Partikel ditunjukkan pada Tabel 1. Berdasarkan Tabel 1 tampak bahwa \%N-gain pemahaman konsep pada topik Kinematika dan Dinamika Partikel secara berturut sebesar $57 \%$ dan $61 \%$, masing-masing berada pada kategori sedang. Berdasarkan Tabel 1, dapat diketahui bahwa pemahaman konsep meningkat dari topik Kinematika ke topik Dinamika Partikel. Berdasarkan \% Ngain yang dicapai, tampak bahwa melalui penerapan pendekatan pemecahan masalah berbasis video pada topik Kinematika dan Dinamika Partikel dapat meningkatkan pemahaman konsep Fisika mahasiswa. 
Tabel 1. Perbandingan Rerata Skor Tes Awal, Tes Akhir, dan \%N-gain Pemahaman Konsep pada Topik Kinematika dan Dinamika Partikel

\begin{tabular}{|l|c|c|c|c|}
\hline \multicolumn{1}{|c|}{ Topik } & $\begin{array}{c}\text { Rerata Skor } \\
\text { Tes Awal }\end{array}$ & $\begin{array}{c}\text { Rerata Skor } \\
\text { Tes Akhir }\end{array}$ & $\begin{array}{c}\text { N-gain } \\
(\%)\end{array}$ & Kategori \\
\hline Kinematika Partikel & 26,70 & 68,72 & 57 & Sedang \\
\hline Dinamika Partikel & 27,94 & 71,54 & 61 & Sedang \\
\hline
\end{tabular}

Keterangan: Skor maksimum $=100$

Gambar 1 menunjukkan perbandingan $\% \mathrm{~N}$-gain pemahaman konsep yang secara rinci dijabarkan berdasarkan indikator setiap aspek pemahaman konsep, yang meliputi menginterpretasi, mencontohkan, membandingkan, mengklasifikasi, menjelaskan, dan menyimpulkan. Berdasarkan Gambar 1, peningkatan \%N-gain pemahaman konsep pada topik Kinematika Partikel untuk setiap indikator menginterpretasi, mencontohkan, membandingkan, mengklasifikasi, menjelaskan, dan menyimpulkan berturut-turut sebesar 51\%, 59\%, 65\%, 55\%, $60 \%$, dan 61\%. Untuk topik Dinamika Partikel, peningkatan \% $\mathrm{N}$-gain pemahaman konsep untuk setiap indikator menginterpretasi, mencontohkan, membandingkan, mengklasifikasi, menjelaskan, dan menyimpulkan berturut-turut sebesar $47 \%, 58 \%, 63 \%, 54 \%$, $55 \%$, dan 64\%.

Berdasarkan Gambar 1, peningkatan \% $\mathrm{N}$-gain pemahaman konsep, baik pada topik Kinematika maupun Dinamika Partikel paling rendah terjadi pada indikator menginterpretasi dan untuk kedua topik ini, peningkatan pemahaman konsep untuk setiap indikator tergolong sedang.

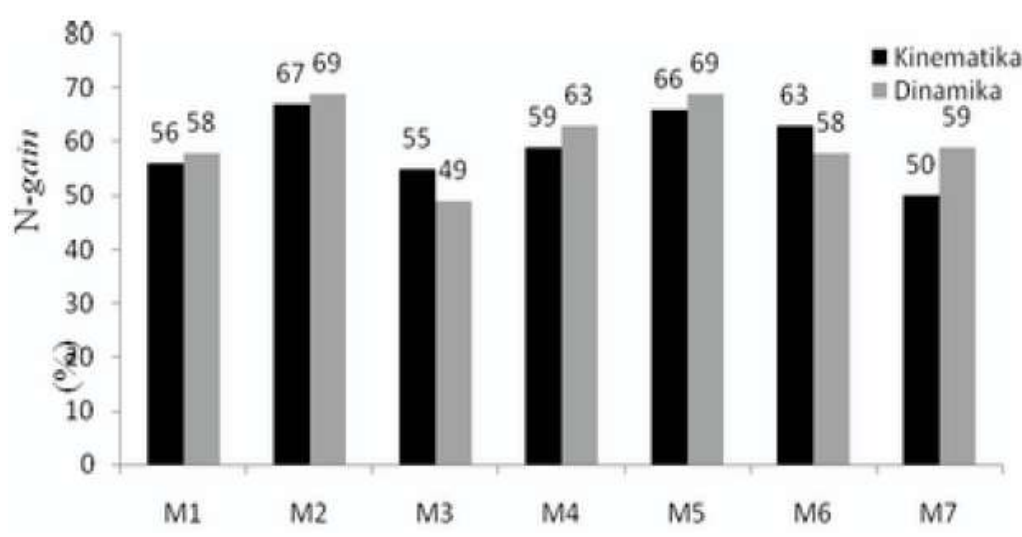

Kemampuan Metakognisi Berdasarkan Indikator Setiap Komponennya

Gambar 1. Perbandingan \%N-gain Pemahaman Konsep Berdasarkan Indikator Setiap Aspeknya pada Topik Kinematika dan Dinamika Partikel. Indikator P1 = menginterpretasi, P2 = mencontohkan, $\mathrm{P} 3=$ membandingkan, $\mathrm{P} 4=$ mengklasifikasikan, P5 = menjelaskan, dan P6 = menyimpulkan.

Gambar 2 menunjukkan perbandingan $\% \mathrm{~N}$-gain pemahaman konsep yang dijabarkan berdasarkan setiap konsep Kinematika dan Dinamika Partikel. Penjabaran konsep pada topik Kinematika Partikel meliputi gerak lurus beraturan (GLB), gerak lurus berubah beraturan (GLBB), gerak vertikal, gerak jatuh bebas, dan gerak peluru. Penjabaran konsep pada topik 
Dinamika Partikel, meliputi Hukum Newton, gaya berat, gaya normal, tegangan tali, dan gaya gesek. Berdasarkan Gambar 2, peningkatan \%N-gain pemahaman konsep untuk topik Kinematika Partikel pada konsep GLB, GLBB, gerak vertikal, gerak jatuh bebas, dan gerak peluru berturut-turut sebesar 57\%, 54\%, 62\%, $60 \%$, dan 56\%. Peningkatan N-gain pemahaman konsep pada topik Dinamika Partikel pada konsep Hukum Newton, gaya berat, gaya normal, tegangan tali, dan gaya gesek berturutturut sebesar $65 \%, 55 \%, 46 \%, 60 \%$, dan $49 \%$. Peningkatan pemahaman konsep, baik pada topik Kinematika dan Dinamika Partikel untuk semua konsep termasuk dalam kategori sedang.

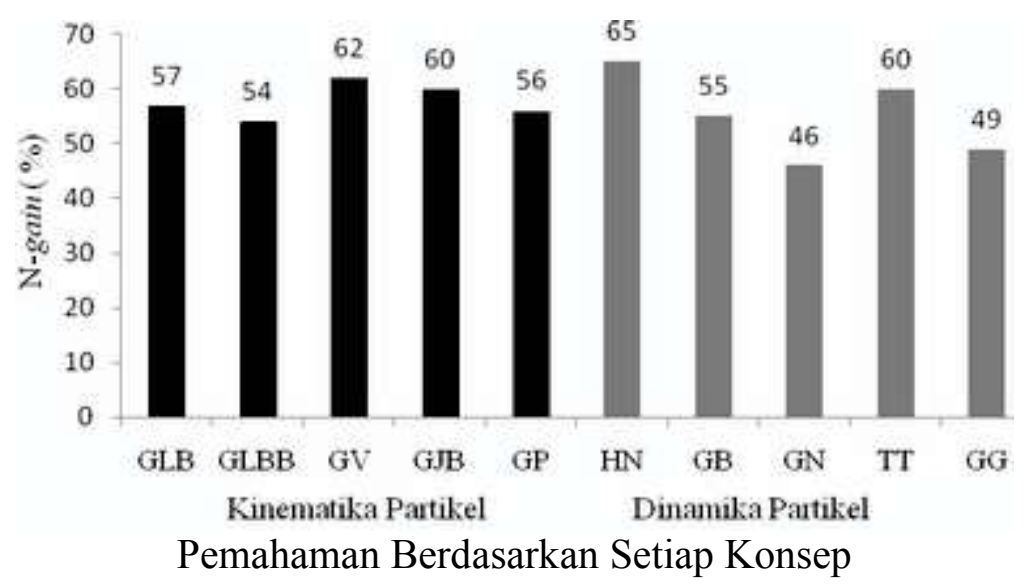

Gambar 2. Perbandingan \%N-gain Pemahaman Berdasarkan Setiap Konsep pada Topik Kinematika dan Dinamika Partikel. Konsep GLB = gerak lurus beraturan, GLBB = gerak lurus berubah beraturan, $\mathrm{GV}=$ gerak vertikal, GJB = gerak jatuh bebas, GP = gerak peluru, $\mathrm{HN}=$ Hukum Newton, GB=gaya berat, GN = gaya normal, TT $=$ tegangan tali, dan $\mathrm{GG}=$ gaya gesek.

Berdasarkan hasil penelitian ini, peningkatan pemahaman konsep melalui pendekatan pembelajaran pemecahan masalah berbasis, baik pada pada topik Kinematika dan Dinamika Partikel berada pada kategori sedang.

Berdasarkan hasil analisis data, ditinjau berdasarkan indikator dalam setiap aspek pemahaman konsep (menginterpretasi, mencontohkan, membandingkan, mengklasifikasi, menjelaskan, dan menyimpulkan) ternyata $\% \mathrm{~N}-$ gain pemahaman konsep paling tinggi pada topik Kinematika Partikel yang dicapai kelompok eksperimen terjadi pada aspek menyimpulkan, termasuk dalam kategori tinggi dan pada topik Dinamika Partikel, peningkatan $\%$ N-gain pemahaman konsep paling tinggi terjadi pada aspek membandingkan dan menyimpulkan, termasuk dalam kategori sedang. Pemahaman konsep paling tinggi, baik pada topik Kinematika dan Dinamika Partikel terjadi dalam hal menyimpulkan, hal ini dapat terjadi karena dalam tahap-tahap pemecahan masalah melalui eksperimen berbasis video yang analisisnya dibantu dengan menggunakan software, mahasiswa dapat menganalisis hasil eksperimennya lebih akurat, mereka dapat menemukan dan mengembangkan konsep serta memberi kesimpulan dari apa yang ditemukan. Selain itu, jika ditinjau dari soal yang mengukur pemahaman konsep dalam aspek menyimpulkan sangat berkaitan dengan hasil eksperimen mahasiswa berbasis video di kelas.

Peningkatan yang paling rendah pada topik Kinematika dan Dinamika Partikel, 
terjadi pada aspek menginterpretasi. Hal ini dapat terjadi karena memang pekerjaan menginterpretasi memiliki tingkat kesulitan yang lebih dibandingkan dengan mencontohkan, membandingkan, mengklasifikasi, dan menjelaskan. Hal ini juga dipengaruhi dari soal yang mengukur pemahaman konsep dalam aspek menginterpretasi, jika dianalisis lebih lanjut masih bersifat umum, kurang berkaitan langsung dengan hasil eksperimen mahasiswa di kelas.

Pemahaman konsep fisika mahasiswa dapat ditingkatkan dengan menerapkan pembelajaran pemecahan masalah melalui eksperimen berbasis video karena: 1) Video dapat digunakan untuk menyelidiki masalah situasi kehidupan nyata dengan menggunakan konsep yang kontekstual; 2) Video dapat menyajikan gerak benda dalam dua dimensi; 3) Evaluasi dari kegiatan ini berpotensi untuk memvisualisasikan, menyelidiki, menganalisis, dan memahami berbagai topik dalam fisika; dan 4) Video ini dapat diotak-atik dengan mudah sehingga dapat memenuhi keinginan mahasiswa untuk mengkonstruksi dan mengembangkan pemahaman konsep mereka (Teese, 2007; Wagner et al., 2006; dan Zollman, 2001).

Melalui proses pemecahan masalah, pemahaman konsep dapat ditingkatkan karena mahasiswa lebih mudah mengkonstruksi pengetahuan, menggali ide-ide yang berkaitan dengan konsep-konsep esensial, memperdalam dan memahami konsep-konsep sehingga ide-ide yang muncul dapat dikembangkan. Hal ini disebabkan karena dalam pembelajaran pemecahan masalah, membimbing mahasiswa menyusun lingkungan belajar dan memilih strategi yang tepat, mahasiswa menjadi semakin percaya diri dan menjadi pebelajar yang mandiri, menyadari bahwa mereka dapat memenuhi kebutuhan intelektual sendiri, menemukan banyak informasi oleh tangan mereka sendiri, dan menyadari bahwa disaat mereka menghadapi masalah akan mencoba mencari jalan keluar. Dengan penyajian masalah, maka rancangan pemecahan masalah dan tahapannya membantu peserta didik mengembangkan rangkaian hubungan kognitif. Dengan mengumpulkan data dan informasi lebih banyak untuk menyelesaikan masalah, peserta didik menerapkan kemampuan berpikir analitis, seperti merepresentasikan, membandingkan, mengklasifikasikan, dan menyimpulkan.

Hal ini didukung oleh Henderson dan Kuo (2001) yang menyatakan bahwa dengan kemampuan memecahkan masalah, membimbing mahasiswa menyusun lingkungan belajar dan memilih strategi untuk memperbaiki kinerja kognisi pada masa yang akan datang dapat meningkatkan hasil belajar, khususnya daya ingat dan pemahaman.

\section{KESIMPULAN}

Berdasarkan hasil penelitian dan pembahasan di atas, maka dapat dikemukakan kesimpulan bahwa melalui pendekatan pembelajaran pemecahan masalah berbasis video mampu meningkatkan pemahaman konsep Fisika mahasiswa, yang ditandai dengan nilai gain yang dinormalisasi baik pada pada topik Kinematika dan Dinamika Partikel berada pada kategori sedang.

\section{DAFTAR PUSTAKA}

Anderson, L. W. and Krathwohl, D. R. (eds). 2002. A Taxonomy for Learning Teaching and Assessing. A Revision of Bloom's Taxonomy of education Objectives. New York: Addisin Wesley.

Kuo, V. 2004. An explanatory model of physics faculty conception about the problem solving process. University of Minnesota: $\mathrm{Ph}$. D. Thesis.

Gardner, H. 1999. The dicipline mind: What all students should understand. New York:Simon \& Schuster Inc.

Hake and Richard, R. 2002. Relationship of Individual Student Normalized Learning Gains in Mechanics with Gender, HighSchool Physics, and Pretest Scores on Mathematics and Spatial Visualization. 
Tersedia:http:// www.physics.indiana.edu / hake. [21 September 2008].

Heller, K., and Heller, P. 1999. ProblemSolving Labs. Introductory Physics I Mechanics. Cooperative Group problemsolving in physics.

Henderson, C., and Kuo, V. 2001. Instructors' Ideas about Problem Solving-Setting Goals. Proceedings of the Physics Education Research Conference, Rochester, NY.

Teese, R. 2007. Video Analysis-A Multimedia Tool for Homework and Class Assignments. 12th International Conference on Multimedia in Physics Teaching and Learning, 13-15 September 2007, Wroclaw, Poland.

Wagner A., Altherr, S., Eckert, B., and Jodl, H. J. 2006. Multimedia in physics education: a video for the quantitative analysis of the centrifugal force and the Coriolis force. Eur. J. Phys. 27 (2006) L27-L30.

Wenning, C. J. 2006. A pramework for teaching the nature of science. Journal of Physics Teacher Education Online. 3(3). 3-10. Available at: http:// www.phy.ilstu. edu/jpteo.

Yulaelawaty, E. 2002. Karakteristik pembelajaran MIPA berdasarkan Kurikulum Berbasis Kompetensi. Makalah. Disajikan pada seminar pembelajaran MIPA di FPMIPA IKIP Negeri Singaraja, 21 Desember 2002.

Zhaoyao, M. 2002. Physics education for the 21st century: avoiding a crisis. Physics Education, 37(1). 7-8.

Zollman, D. A. 2001. Modeling Real World Events and Video Data Collection. http://www.phys.ksu.edu/perg. 